\title{
IGUALDADE COMO IDEAL
}

\section{Entrevista com Ronald Dworkin}

\begin{abstract}
RESUMO
$\mathrm{Na}$ entrevista a seguir, o filósofo e jurista norte-americano Ronald Dworkin discorre sobre temas recorrentes em sua obra. Ele reafirma que a igualdade de riquezas em si não tem jamais valor intrínseco e esclarece a natureza e as implicações práticas do "seguro hipotético" — sua complexa construção teórica para a implementação do ideal da igualdade no campo econômico.
\end{abstract}

PALAVRAS-CHAVE: Direito; filosofia; igualdade; Ronald Dworkin.

\section{SUMMARY}

In the following interview, Ronald Dworkin discusses recurrent topics of his work. He reaffirms that equality of resources has no intrinsical value and reveals the nature and practical implications of "hypothetical insurance" - his complex theoretical construction for the implementation of the ideal of equality in economical field.

KEYWORDS: Law; philosophy; equality; Ronald Dworkin

Em A virtude soberana, o filósofo e jurista norte-americano Ronald Dworkin, um dos principais expoentes do igualitarismo liberal anglo-saxão, desenvolve a teoria sobre o ideal da igualdade e discute a aplicação desse ideal a alguns dos debates mais importantes que freqüentaram a cena política dos Estados Unidos nas duas últimas décadas. Nesta entrevista, concedida com exclusividade à Revista Novos Estudos, ele reafirma que a igualdade de riquezas em si não tem jamais valor intrínseco e esclarece a natureza e as implicações práticas do "seguro hipotético" - sua complexa construção teórica para a implementação do ideal da igualdade no campo econômico. Dworkin também comenta a aplicação da igualdade em campos específicos, como o da saúde e o das ações afirmativas. Defende-se das críticas de que sua proposta é conservadora, nega que a 14-emenda da Constituição americana ("equal protection clause") enseja direitos econômicos e sociais, e afirma que o ideal da igualdade não se aplica às relações privadas nem à questão da justiça internacional. Em alusão à sua controvertida posição sobre a objetividade dos valores morais, chega a afirmar que "temos a verdade do nosso lado". (Octávio Luiz Motta Ferraz) 
Octávio Ferraz - Tocqueville escreveu na introdução de Democracia na América que nada do que viu nos Estados Unidos dos anos 1830 lhe impressionou tanto como a "igualdade de condições" dos cidadãos. Os EUA são hoje o país desenvolvido mais desigual do mundo. Sua teoria sobre a igualdade distributiva é compatível, pelo menos em princípio, com desigualdades de riquezas significativas, como as existentes nos EUA e em países como o Brasil. Se os talentosos ficam muito ricos e os não-talentosos são deixados para trás, desde que os últimos sejam compensados pelos primeiros por um sistema de beneficios sociais financiado por impostos progressivos modelado em seu mecanismo hipotético de seguro, a igualdade é respeitada. Não há um ponto além do qual as desigualdades de riquezas se tornam intrinsicamente erradas?

Ronald Dworkin - Eu acho que não. Em $A$ virtude soberana, observo que transferências dos ricos para os pobres inevitavelmente desfavorecem alguns destes últimos. Então essas transferências precisam de uma justificativa, e a justificativa do seguro foi a melhor que pude construir. Talvez haja uma justificativa melhor para transferências além do ponto do seguro, mas eu não sei qual é.É claro que as desigualdades dos Estados Unidos atual e do Brasil não poderiam de modo algum ser justificadas com o modelo do seguro. Nem as desigualdades de qualquer outro país onde exista grande quantidade de riquezas. Portanto, o modelo do seguro é bastante radical, porém é diferente da igualdade estrita.

Nas linhas iniciais de A virtude soberana você diz que a igualdade é a "espécie em extinção dos ideais políticos" e questiona se a igualdade realmente tem importância. No entanto, muitas pessoas que aceitam a igualdade de consideração como uma virtude fundamental têm a intuição de que no campo econômico o que de fato importa não éalguns terem mais que outros (mesmo que essas desigualdades decorram de fatos moralmente arbitrários, como a pura sorte), mas simalguns (ou melhor, muitos, no mundo real) não terem o suficiente nem mesmo para satisfazer às necessidades básicas. Seu livro parece pregar aos convertidos abordando a questão "igualdade de quê"? Mas o que você teria a dizer aos que perguntam "por que a igualdade"? Em que o resultado prático de sua teoria difere de uma garantia das necessidades básicas mínimas? No mundo contemporâneo, eliminar a fome e outras privações extremas nos tornaria muito mais próximos do ideal do seguro, e talvez, sob uma perspectiva prática, devêssemos todos nos concentrar nisso. Como até mesmo esse objetivo éidealista, pode parecer tolo nos preocuparmos com mais igualdade do que isso. No entanto, da perspectiva filosófica isso é importante, porque é importante enfatizar que o princípio diretor é o da igual consideração. Suponha que as necessidades básicas de todos estivessem garantidas, mas que algumas pessoas 
[1] "Equality, luck and hierarchy", Philosophy \& PublicAffairs,31, n.2,p.191. tivessem um leque de oportunidades muito mais rico do que outras. Isso teria que ser justificado como consistente com a igual consideração para todos. Poderia ser realizado se o modelo do seguro ou algo parecido fosse implementado, mas não de outro modo.

Contra as críticas de que a "igualdade de recursos" é muito rigorosa, pois as pessoas que escolhessem não comprar o seguro (num mercado real, apesar de improvável) estariam "ao Deus dará" em casos de emergência, você responde que "uma comunidade compromissada com a igualdade de recursos teria ampla justificativa para requerer que as pessoas comprassem [compulsoriamente] seguro para cuidados médicos básicos". Mas será que a igual consideração requer mesmo isso, ou será que há outro princípio moral que o requer? Talvez pudéssemos chamá-lo solidariedade ou compaixão. Se aceitarmos que a distinção "escolha/circunstância" representa o critério fundamental (ou ao menos exerce papel importante) para a justiça distributiva, parece implausível dizer que resgatar as pessoas de suas escolhas ruins é uma questão de justiça, e não de solidariedade. Em outras palavras, não se trata de uma questão de igual consideração, mas de simples consideração.

A hipótese é muito fantasiosa, porque é extremamente improvável haver uma comunidade na qual as condições ideais do modelo do seguro realmente operassem, de modo que a comunidade pudesse se valer de transações de seguro reais, e não hipotéticas. Mesmo nessa comunidade, igual consideração implicaria consideração, e consideração justificaria algo que em $A$ virtude soberana eu chamo de paternalismo superficial. Isso incluiria um seguro básico obrigatório. Mas a comunidade teria outras razões também: o mal-estar de uma pessoa não prejudica apenas ela. Acredito, portanto, que haveria uma variedade de justificativas para um seguro obrigatório.

A idéia central do chamado igualitarismo liberal é que desigualdades econômicas são justificadas desde que resultem das escolhas das pessoas, não de suas circunstâncias (ou o que você chama em certas passagens de pura má sorte). Mas o mecanismo do seguro hipotético equaliza as pessoas apenas em relação aos recursos com os quais elas enfrentam riscos (ex ante), e não em relação à situação na qual se encontram depois que os riscos se materializam de forma diversa para pessoas diferentes (ex post). Aleitura mais natural do seguro hipotético em Avirtude soberana parece ser de que ele é uma opção realista, porém não ideal (é muito custoso ou impossivel separar escolha e circunstância, é impossivel equalizar ex post etc.). Contudo, recentemente você sustentou que o mecanismo do seguro não é uma "solução de transigência ou second-best que aceita alguma injustiça por necessidade. É o que a igualdade, propriamente entendida, efetivamente requer" ". Você mudou de opinião sobre esse ponto? 
Creio que meus comentários mais recentes, em resposta às críticas que recebi, apenas tornam claro o que $A$ virtude soberana supõe. Por diversas razões, seria tanto irracional como injusto - e uma violação dos dois princípios que eu entendo sustentar o igualitarismo liberal - buscar compensação ex post para a pura má sorte. Espero que os leitores vejam meu novo livro, Is Democracy Possible Here?, no qual explico o porquêem mais detalhes. Mas acho que o argumento básico já está claro no capítulo 8, e especialmente no 9, de A virtude soberana.

Em países muito desiguais, como o Brasil e em certa medida os Estados Unidos, não se pode deixar de perceber que a maior parte dos pobres são "formigas", e não "cigarras", e que a pobreza decorre da ausência de oportunidades reais, e não de deficiências, gostos dispendiosos, falta de esforço, ou mesmo falta do que você chama de talento-riqueza. Sem ignorar a importância desses temas para refinar nossas intuições sobre a justiça, A virtude soberana $e$ outros trabalhos na literatura anglo-americana do igualitarismo podem parecer às vezes um pouco distantes do que foi chamado de objeto principal da justiça, isto é, "arranjos institucionais que geram as oportunidades das pessoas ao longo do tempo" 2 . Há pouca discussão, por exemplo, sobre o papel igualitário de um sistema universal de educação primária e secundária, assunto calorosamente debatido nos $E U A$, onde as escolas públicas são financiadas por impostos sobre imóveis, criando uma enorme desigualdade em oportunidades educacionais entre áreas ricas e pobres. Você aceita esse tipo de crítica?

Não vejo por que isso seria uma crítica. Espero que minha impossibilidade de discutir todos os tópicos relacionados à distribuição de renda não signifique que os considere irrelevantes. Na primeira parte do livro, me concentrei na estrutura filosófica, e depois, para ilustrar, na segunda parte discuti uma variedade de temas políticos. Poderia ter abordado muitos outros temas na segunda parte, mas a primeira, em especial o capítulo 3, deixa clara a importância de instituições estruturais, incluindo a educação.

As políticas públicas que você recomenda para a implementação da igualdade de recursos não ofenderiam os azarados?? Parece correta a afirmação de que a "falácia de que ajudar os azarados os insulta foi, por séculos, um pretexto para a indiferença dos ricos, não para a indignidade dos pobres" 4 , especialmente na história anglo-americana. Mas a escolha de instrumentos institucionais para implementar a igualdade de recursos tem implicações importantes para o ideal da igual consideração. Quando o mercado é usado como principal árbitro da alocação de recursos e as desigualdades resultantes são corrigidas com impostos e redistribuição, estamos apoiando um sistema de ganhadores e perdedoresno qual, em intervalos periódicos dojogo, os perdedores recebem uma
[2] Anderson, Elizabeth. "What is the point of equality?" Ethics, jan. 1999, p.309.

\footnotetext{
[3] $\operatorname{Em} A$ virtude soberana, azarados tem conotação técnica. São os que perdem no jogo do mercado por circunstâncias fora de seu controle.

[4] "Sovereign virtue revisited", Ethics, out. 2002, p. 116.
} 
espécie de "caridade" dos ganhadores. Se, de acordo com a igualdade de recursos, essa "caridade" é na verdade a parte justa a que os "perdedores" têm direito e o que os "ganhadores" não podem reclamar como seu, parece mais adequado à igual consideração um sistema diferente, no qual algo mais próximo de uma distribuição justa pudesse ser alcançado sem necessidade de redistribuição. Dois exemplos dessas opções são leis estabelecendo um salário mínimo e preços máximos para certos produtos e serviços essenciais. Você chega a mencionar essas opções em passagens de A virtude soberana, mas a ênfase é posta em políticas de taxação e redistribuição, levando alguns críticos a dizer que essa obra e outras versões do igualitarismo liberal são apologias do status quo (ou seja, do capitalismo mitigado por beneficios de seguridade social). Por que esses críticos estão errados?

Eles estão errados porque o meu argumento condena de forma clara o status quo. Em hipótese alguma o aceita. Se meus argumentos estão corretos, os remédios para a desigualdade que distorcem mercados são na verdade antiigualitários. Eles acabam por prejudicar algumas pessoas extremamente desfavorecidas em prol de outras; freqüentemente em prol de outras não tão desfavorecidas. Leis impondo um salário mínimo são um bom exemplo: são muito ruins para imigrantes e trabalhadores sem qualificações. Controle de preços é pior ainda, como a história do socialismo mostra. Por distorcer a estrutura de escolha, implica que algumas pessoas pobres - aquelas cujos gostos não são subsidiados - não terão o que a justiça lhes concede. Acho que em $A$ virtude soberana fica claro, no entanto, que muitas vezes tais remédios são necessários, porque são os únicos que ajudarão. Esseéo assunto da minha discussão sobre as imperfeições do mercado no capítuloz eem outros pontos do livro. Mas devemos em princípio preferir distribuição pós-mercado por meio de um sistema de impostos: é mais justo para todos, incluindo os mais desfavorecidos. Penso que são sobretudo os ricos que consideram caridade os programas de bemestar financiados por impostos. Seéisso que a justiça demanda, temos que ser capazes de impedi-los de persuadir os beneficiários de que se trata de caridade. Temos a verdade do nosso lado, e é melhor do que perpetuar a injustiça.

No campo específico da saúde, você defende no capítulo 8 um sistema no qual todos tenham direito ao que o seguro hipotético recomendaria e então as pessoas estejam livres para adquirir mais serviços de saúde no setor privado. Isso seria certamente um progresso nos Estados Unidos, onde se diz que mais de 40 milhões de americanos não têm seguro-saúde. Mas pode parecer a muitas pessoas que outros sistemas seriam mais igualitários do que o seu. Cito como exemplo o Serviço Nacional de Saúde britânico (National Health Server, NHS) e outros na Europa, nos 
quais o Estado garante um pacote generoso de serviços de saúde à população (talvez acima do que o seu mecanismo de seguro faria) e o sistema privado é marginal (garantindo basicamente acesso mais rápido). No capítulo 3 você reconhece que o ideal da igualdade pode até mesmo justificar a proibição completa de saúde privada, se isso resultasse em melhor qualidade do sistema público. O que, além de pragmatismo politico, poderia nos levar a escolher o sistema híbrido do capitulo 8 sobre o do capítulo 3, ou algo como o sistema europeu, para a implementação da igualdade de recursos?

$\mathrm{Na}$ verdade, acho que o NHS britânico fica muito aquém do que o modelo do seguro justificaria. É isso que nos faz dizer que ele está gravemente subfinanciado, idéia amplamente aceita. Suponha que um sistema justo de seguro estivesse de fato em funcionamento como um serviço de saúde com financiador único. Suponha também que o tipo de taxação redistributiva que eu recomendo estivesse em vigor, de modo que as enormes desigualdades de riquezas que hoje estragam nossas sociedades tivessem sido eliminadas. Por que não deveríamos permitir que as pessoas gastassem seu excedente como quisessem? Algumas em casas maiores, outras em férias, outras com mais segurosaúde.Assim, minha sugestão parece melhor quando vista como parte de um sistema geral da justiça distributiva. Há outras vantagens a todos, além daquelas que descrevo. Tratamentos experimentais caros podem ser testados no setor privado, por exemplo, e tornar-se mais baratos mediante economias de escala, de modo a poderem ser introduzidos no sistema geral. Mas, como sempre, quero enfatizar principalmente o argumento da justiça.

Muitos ordenamentos jurídicos reconhecem expressa ou implicitamente os direitos econômicos e sociais, que são vistos como direitos que implementam a igualdade. Ao contrário de outros constitucionalistas americanos, você não vê a 14ª emenda à Constituição dos Estados Unidos como fundamento para um direito a alguma forma de igualdade econômica. Ao elogiar a decisão da Suprema Corte em Romer v. Evans (declarando inconstitucional uma lei do Colorado que proibia proteção especial aos homossexuais), você diz que "foi uma vitória do movimento da integridade [para quem "se os direitos constitucionais reconhecidos a um grupo pressupõem princípios mais gerais que fundamentariam outros direitos constitucionais para outros grupos, então estes últimos têm que ser reconhecidos e implementados também"] e para a convicção de que a igualdade é um princípio não só de justiça, mas também de direito constitucional". Salvo um argumento de incapacidade institucional do Judiciário para lidar com questões de justiça distributiva ${ }^{5}$, é dificil entender como o movimento da integridade pode elogiar Romer v. Evans sem ao mesmo tempo desaprovar decisóes como San Antonio
[5] Dworkin parece apresentar essa visão em "Response to overseas commentators", The International Journal of Constitutional Law, vol. 4, n. 1 . 
Indep. Sch. Dist. v. Rodriguez e outras, que negam que a $14^{\underline{a}}$ emenda enseje qualquer tipo de direito positivo à igualdade em recursos educacionais e outros. Não há contradição na sua teoria sobre a interpretação dos direitos constitucionais americanos?

$\mathrm{Na}$ minha opinião, Rodriguez estava errado quando foi decidido, mas essa decisão, que desde então foi repetida com inúmeras variantes, me impede de negar que a cláusula da "proteção igual" (equal protection) agora pode ser interpretada como você sugere. Acho que a melhor justificação do direito requer o reconhecimento do que chamo de direito à independência moral: direito de liberdade para tomar decisões de moralidade pessoal que afetam principalmente o indivíduo (retorno esse assunto no meu livro novo, Democracy.) Creio que foi esse direito reconhecido nos casos sobre o aborto - que justificou a decisão em Romer e Lawrence. Ele não se aplica à provisão de educação pública.

Atualmente a sociedade brasileira está dividida entre os favoráveis e os contrários a dois projetos de lei (Lei das Cotas e O estatuto da igualdade racial) que tornarão obrigatórias algumas ações afirmativas na forma de cotas para pessoas da raça negra (20\%) em educação, cargos públicos, empresas privadas, programas de televisão e propagandas. Ambos os lados usam o ideal da igualdade como principal argumento para aceitar ou repudiar os projetos. Em A virtude soberana você discute o assunto no contexto americano, mas a igualdade surpreendentemente não figura como argumento favorável ou contrário. Você defende a ação afirmativa nas universidades como necessária para alcançar a diversidade e a justiça social no futuro, não para compensar os negros por discriminação presente ou passada. E sustenta que os brancos não têm direito a um sistema de alocação de vagas universitárias que desconsidere a raça do candidato. Odebate brasileiro está mal colocado ou você buscou minimizar a importância da igualdade devido às circunstâncias particulares dos Estados Unidos?

Não posso comentar o caso brasileiro. Não conheço bem as circunstâncias e os argumentos. Mas penso que é um grande erro tentar defender a ação afirmativa como uma compensação para injustiças do passado. Não encaixa: quem se beneficia não é quem sofreu no passado. E creio ser um equívoco supor que uma parte da população - em vez de indivíduos - possa ser detentora de direitos, como o direito à compensação. Porém, é claro que a igualdade está presente no meu argumento prospectivo para a ação afirmativa. Eu defendo que uma sociedade sem preconceito racial e sem estereótipos tem probabilidade maior de ser justa na distribuição de riquezas e também tem maior probabilidade de ser melhor para todas as pessoas, em muitos outros aspectos. Parece-me que a questão ao Brasil é se as cotas em discussão tornariam a sociedade melhor no futuro, nesses 
aspectos. Não acho que um suposto direito à compensação deveria figurar no argumento.

Ao sustentar que a igualdade é a virtude dos soberanos, você em princípio restringe sua aplicação ao relacionamento entre governo e seus cidadãos. A legitimidade politica é certamente um argumento sólido para defender a igualdade. Mas será que o ideal da igualdade não tem lugar também na esfera privada e na esfera internacional?

Essa é uma questão muito ampla para uma resposta curta, mas devo deixar claro que não acredito (como os utilitaristas e outros filósofos) que temos o dever pessoal de mostrar igual consideração a todos em tudo que fazemos. Eu tenho direito de favorecer meus filhos em relação aos seus, não porque eles sejam em qualquer sentido mais importantes sob uma perspectiva impessoal, mas porque são os meus filhos. Mas há um limite para o favoritismo que posso mostrar, e esse limiteé particularmente importante na esfera internacional. Pretendo escrever sobre a justiça internacional no futuro, mas não considero que $A$ virtude soberana tenha algo muito útil a dizer sobre o assunto.

Recebido para publicação

em 16 de setembro de 2006.

\section{NOVOS ESTUDOS}

CEBRAP

77 , março 2007

pp. $233-240$ 